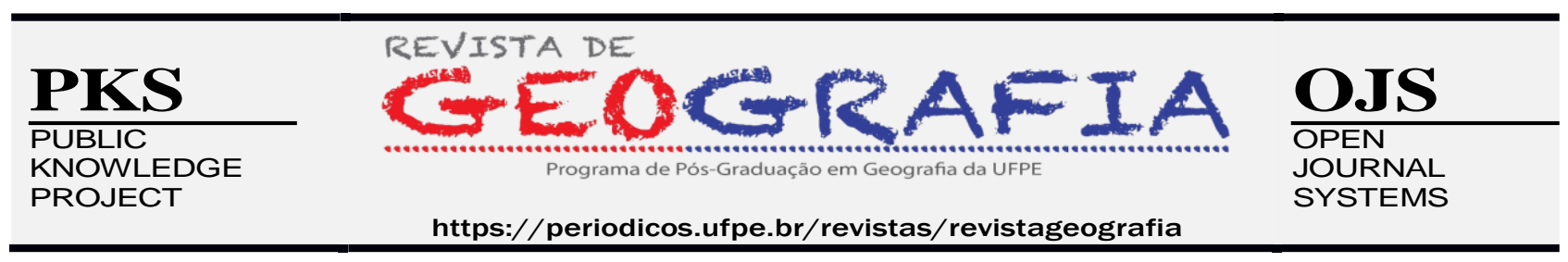

\title{
LIMITES E DESAFIOS NO USO DAS TICs PARA A PRÁTICA DOCENTE DE GEOGRAFIA NA RMR DE RECIFE - PE
}

\author{
Luiz Carlos dos Prazeres Serpa Alfino ${ }^{1}$, Rodrigo Dutra Gomes ${ }^{2}$ \\ 1 Doutor em Geografia pelo Programa de Pós-graduação em Geografia da Universidade Federal de Pernambuco. Email: \\ lcserpa2000@yahoo.com.br. https://orcid.org/0000-0002-9217-941X \\ ${ }^{2}$ Professor e pesquisador do Programa de Pós-Graduação em Geografia da Universidade Federal de Pernambuco. E- \\ mail: rodrigo.dutragomes@ufpe.br. https://orcid.org/0000-0001-6452-3933
}

Artigo recebido em 13/09/2011 e aceito em 05/01/2020

\begin{abstract}
RESUMO
Com o advento da Sociedade Informacional, no transcurso do século XX ao XXI, a integração das TIC (Tecnologia de Informação e Comunicação) no ensino de Geografia trouxe a consciência dos limites e apresentou grandes desafios à prática docente. O objetivo do trabalho foi investigar a incorporação das TIC na prática dos professores de Geografia, nas escolas técnicas e de referência da RMR, buscando compreender limites e desafios. Além de pesquisas de outras experiências foram realizadas entrevistas com professores das EREMs e ETEs de Recife, e posterior comparação e discussão dos dados. Constatou-se que limites e desafios no processo de integração das TIC, no ensino de Geografia, têm sido percebidos como um fenômeno global, que envolve desde implicações na formação, a dificuldades ao nível do ensino e da infraestrutura presentes na realidade sociocultural dos professores. Percebeu-se que o ensino com as TIC requer conhecimento técnico e pedagógico, sistematizado em uma base teórico-metodológica para que resultados promissores sejam alcançados. A irreversibilidade das tecnologias na Sociedade Informacional tem exigido dos professores seu enquadramento em uma linguagem tecnológica, o que constitui um dos grandes desafios, sem o qual a reflexividade e criatividade de sua prática não ocorrem.
\end{abstract}

Palavras-chave: TIC (Tecnologia de Informação e Comunicação), Prática Docente, Professores de Geografia, Limites e Desafios.

\section{LIMITS AND CHALLENGES IN THE USE OF ICTS FOR THE TEACHING PRACTICE OF GEOGRAPHY IN THE RMR OF RECIFE - PE}

\begin{abstract}
With the advent of the Information Society, in the course of the 20th to the 21st century, the integration of ICT (Information Comunication Technology) in the teaching of Geography brought great challenges to teaching practice. The objective of this work was to investigate the incorporation of ICT in the practice of Geography teachers, in the RMR technical and reference schools, seeking to understand limits and challenges arising from the use of ICT. In addition to researching other experiences, interviews were conducted with teachers from the EREMs and ETEs in Recife, and subsequent comparison and discussion of the data. It was perceived that teaching with ICT requires technical and pedagogical knowledge, systematized on a theoretical-methodological basis for promising results to be achieved. It was verified that
\end{abstract}


geospatial technologies are transforming instruments for teaching practice, allowing greater dynamism and interaction in the teaching-learning process. The irreversibility of ICT in society has required teachers, their framing in a technological language, which is one of the great challenges without which the reflexivity and creativity of their practice does not occur.

Keywords: ICT (Information and Communication Technology), Teaching Practice, Geography, Limits and Challenges.

\title{
LÍMITES Y DESAFÍOS EN EL USO DE LAS TIC PARA LA PRÁCTICA DIDÁCTICA DE LA GEOGRAFÍA EN LA RMR DE RECIFE - PE
}

\begin{abstract}
RESUMEN
Con el advenimiento de la Sociedad de la Información, en el transcurso del siglo XX al XXI, la integración de las TIC (Tecnología de la información y la comunicación) en la enseñanza de la Geografía generó conciencia de límites y presentó grandes desafíos para la práctica docente. El objetivo del trabajo fue investigar la incorporación de las TIC en la práctica de los profesores de Geografía, en las escuelas técnicas y de referencia de la RMR, buscando comprender límites y desafíos. Además de la investigación de otras experiencias, se realizaron entrevistas con los profesores de las EREM y ETE de Recife, y posterior comparación y discusión de los datos. Se encontró que los límites y desafíos en el proceso de integración de las TIC, en la enseñanza de la Geografía, han sido percibidos como un fenómeno global, que va desde implicaciones para la formación, hasta dificultades en materia de educación e infraestructura presentes en la realidad sociocultural de los docentes. Se reconoció que la enseñanza con TIC requiere de conocimientos técnicos y pedagógicos, sistematizados sobre una base teórico-metodológica para lograr resultados prometedores. La irreversibilidad de las tecnologías en la sociedad de la información ha obligado a los docentes a encajar en un lenguaje tecnológico, lo que constituye uno de los grandes desafíos, sin el cual no se da la reflexividad y creatividad de su práctica
\end{abstract}

Palabras clave: TIC (Tecnologías de la Información y la Comunicación), práctica docente, geografía, límites y desafíos

\section{INTRODUÇÃO}

A incorporação das Tecnologias de Informação e Comunicação (TIC) na prática docente tem sido um dos principais desafios enfrentados pelos professores de Geografia no atual contexto da Sociedade Informacional, trazendo diversas possibilidades didáticas. Para Pernambuco, a incorporação das TIC é considerada no Plano Estadual de Ensino (2015-2025) como uma das principais estratégias para o salto qualitativo no ensino no estado. $\mathrm{O}$ estado lidera a qualidade da educação básica e média no Brasil pelos dados do IDEB 2015. Mas em termos efetivos ainda é incipiente a presença das TIC no processo pedagógico, em destaque nas escolas de referência (EREMs) e escolas técnicas (ETEs) da Região Metropolitana do Recife (RMR), cujo ensino está classificado como um dos melhores do estado. Apesar dos bons índices alcançados, ainda existem diversos limites e desafios que precisam ser enfrentados para que, a partir das TIC, a prática docente e ensino possam melhorar em conteúdo e dinamismo.

Esses limites e desafios têm sido observados da escala global em diferentes países, no Brasil à escala local, em Pernambuco e Recife - se expressando nas EREMs e ETEs. Muitos desses limites e desafios são decorrentes do próprio processo de implantação da informática na educação básica, 
como, por exemplo, uma deficiente formação do professor (acadêmica e continuada) ainda não adaptada, infraestrutura inadequada das escolas, com ambientes fracamente informatizados para o ensino, com a falta de hardwares e softwares, má qualidade ou ausência de internet, falta de suporte técnico e demais recursos tecnológicos. De igual modo, não se pode deixar de considerar as dificuldades provenientes da falta de "experiência" e de "habilidade" do professor, intensificada por uma formação inadequada para o uso das ferramentas tecnológicas.

Em termos de limites e desafios, apresentam tanto o problema de lidar com os aspectos instrumentais, estruturais e normativos mais rígidos da educação para a incorporação das tecnologias, quanto a exigência de novas posturas pedagógicas, de autoavaliação, de reflexividade das próprias atitudes no planejamento e execução da prática docente. Na Geografia, a tecnologia vem ao encontro de novas perspectivas que visam a dinamizar o processo ensino/aprendizagem, através de instrumentos didático-interativos auxiliares, deparando-se, ao mesmo tempo, com o surgimento daqueles limites e desafios já destacados. Diante desse quadro, a possibilidade de investigar estes novos cenários e práticas que incidem sobre o trabalho dos professores de Geografia nas EREMs e ETEs da RMR permitirá obter conhecimento para se pensar e depois orientar, a partir de Cursos, Oficinas Didáticas etc, a incorporação e a prática desses recursos nas escolas. Dessa forma, há a necessidade de compreender como a inserção das TIC no ensino de Geografia, nas EREMs e ETEs da RMR, em termos de limites e desafios.

Entender como as TIC chegam no "chão" da sala de aula permitirá, em perspectiva, a construção de referenciais para orientar uma proposta de metodologia para o uso destas tecnologias, contrariando a ideia de uso arbitrário da tecnologia e dando um sentido motivacional enquanto dispositivo didático-pedagógico. Para isso, é necessário compreender como os professores de Geografia da educação básica concebem o uso das tecnologias, bem como sua percepção sobre a contribuição das TIC, suas habilidades e competências, além dos limites e desafios enfrentados.

Diante dessa problemática, podemos perguntar: Como, em termos de limites e desafios se dá a incorporação das tecnologias da informação e comunicação na prática de ensino dos professores de Geografia, e em específico, nas escolas técnica e de referência da RMR? Quais os espaços utilizados pelos professores da educação básica para o uso das TIC? Quais os limites e quais as dificuldades específicas enfrentadas pelos docentes das EREMs e ETEs quanto à aplicação de recursos tecnológicos (digitais) como parte integrante de sua prática pedagógica na sala de aula? Como os professores de Geografia da RMR tem pensado a incorporação das TIC no ensino e prática docente? Para responder estar questões buscou-se investigar a incorporação das Tecnologias da 
Informação e Comunicação na prática dos professores de Geografia, em destaque as escolas técnicas (ETEs) e de referência (EREMs) da RMR, buscando compreender os limites e desafios decorrentes.

Ao todo, o percurso metodológico empírico nas escolas foi dividido em 04 (quatro) etapas. $\mathrm{Na}$ primeira etapa, após o diagnóstico das 03 (três) primeiras classificações no IDEPE 2016, nas GREs que participam da RMR, realizou-se um recorte da localização das escolas técnicas e de referência da RMR que serão objetos de estudo. Oficializou-se a pesquisa com a entrega da Carta de Anuência aos gestores das escolas, seguida de uma entrevista informal com o gestor ou seu assistente e o professor de Geografia, apresentando nossa proposta de trabalho e procedimentos metodológicos a serem adotados, assim como os prazos a serem realizados e o compromisso de um feedback dos resultados obtidos na pesquisa para a reflexividade docente.

\section{Os limites do uso das TIC na prática dos professores de Geografia nas EREMs e ETEs da RMR}

Os limites com o uso das TIC para a prática dos professores de Geografia, muitas vezes, antecedem a própria formação acadêmica e seu percurso. Influenciado por uma concepção técnica, a constituição do currículo nas Instituições de Ensino Superior apresenta limites para uma formação que bem qualifique o futuro docente. Ainda há restrições a superar para garantir as competências e habilidades adequadas para o uso dos recursos didático-interativos na prática docente. Vinculado à formação, existe também o problema do pouco tempo para o aperfeiçoamento no uso dessas ferramentas tecnológicas, bem como o pequeno apoio técnico para sua manutenção. Além das questões relacionadas à competência e habilidades para o aprimoramento de seu desenvolvimento pedagógico e profissional, têm sido observadas questões relacionadas à falta de acessibilidade e a falta de confiança dos professores em utilizar as ferramentas tecnológicas, incluindo softwares e hardwares. Esses três aspectos - currículo, falta de acessibilidade e falta de confiança - estão interconectados, com a dificuldade do primeiro e segundo se repercutindo no terceiro. Os limites do primeiro se ligam muito à inflexibilidade das normas vigentes que buscam parâmetros técnicos, meritocrático e competitivos para lidar com as novidades trazidas pelas TIC; e os limites do segundo e terceiro ligado às barreiras e dificuldades.

O currículo é o primeiro ponto de análise. Frente ao contexto da Revolução Tecnológica e Globalização é fundamental para a formação do professor de Geografia incluir conhecimentos mais específicos sobre as TIC. É uma estratégia frente a sua profissão, a fim de oferecer maiores 
competências e qualificações para o desempenho das atividades docentes com o uso dos recursos tecnológicos. E, no curso da formação do professor, obter maiores informações técnicas e operativas associadas a conhecimentos e saberes didático-metodológicos para sua prática. Para verificar a situação do currículo de formação do professor, foram pesquisadas, nas principais universidades federais e estaduais do Nordeste, os componentes curriculares dos cursos de Licenciatura em Geografia. Apurou-se que existem cursos que ainda não dispõem de nenhum componente curricular na área de tecnologia na formação dos professores. Constatamos, também, que, em mais de 60\% das universidades federais pesquisadas, os componentes curriculares são optativos, possibilitando que muitos graduandos possam se formar sem os mínimos conteúdos técnicos e pedagógicos ligados à TIC.

A pesquisa apresentada por Santos S. (2014) realça essa defasagem ao apresentar a inexistência de componentes curriculares obrigatórios sobre o uso das TIC no ensino de Geografia. Ao consultar a matriz curricular do curso de Licenciatura em Geografia em 05 (cinco) universidades públicas brasileiras, distribuídas entre as regiões sudeste e centro-oeste do Brasil, constatou-se que nas matrizes curriculares não são ofertados componentes obrigatórios para a introdução das TIC na formação do professor de Geografia. Assim, conforme o referido autor:

Das matrizes curriculares consultadas, nenhuma oferece, em regime obrigatório, uma disciplina própria para introduzir as TICs no processo de formação do professor de geografia. Observei que o tema tecnologia é abordado em disciplinas como "Didática" e "Introdução à informática". Apenas o curso de licenciatura em geografia da Universidade Federal do Rio de Janeiro oferece, como crédito optativo, a disciplina Tecnologia da Informação e Ciberespaço, com carga horária de 30h (SANTOS, S., 2014).

Nestas condições, há um possível "deficit" na formação docente, para o uso dos recursos tecnológicos em sua prática de ensino. As possíveis consequências se estendem para outros campos: das competências, das habilidades e da falta de confiança dos professores para o efetivo uso desses recursos em sua prática docente.

As competências e habilidades encontram-se diretamente articuladas no processo de formação do professor. A competência encontra-se relacionada ao conhecimento sobre algo, a capacidade de realizar ações embasadas em saberes construídos ao longo da vida. São provenientes da formação e da experiência, decorrendo em formas de percepção da realidade, fruto das inquietudes e reflexões humanas se materializando em ações e atitudes. A capacidade de adquirir aptidão e realizar essas ações com destreza é uma característica das habilidades - as competências resultam, assim, em habilidades. 
É justamente no processo de qualificação dos saberes docentes, alinhados a princípios epistemológicos e empíricos, que se manifestam no processo didático-pedagógico na articulação das competências e habilidades. Nesse sentido, a formação não adequada para o uso das TIC na universidade, apenas de maneira instrumental, sem estruturar competências e desenvolver habilidades, resultará numa simples aquisição mecânica e repetitiva de práticas, restando poucos meios de autorreflexão e criatividade no planejamento das aulas. E isso tanto para os conhecimentos e práticas técnicas, quanto pedagógicas, em ambas as situações, limitando a articulação entre as competências e habilidades na prática docente (SANTOS, 2013).

Partindo para a prática docente, de acordo com os autores, o desenvolvimento destas competências e habilidades no ensino das TIC passa por dificuldades ligadas basicamente a dois aspectos: a infraestrutura e o ensino (BINGIMLAS, 2009, CHEN e TAN E LIM, 2012, DESAI e MORE, 2014). Segundo Bingimlas (2009), o processo de integração das TIC na prática de ensino dos professores é algo complexo e apresenta um número de dificuldades no fluxo do ensino. As dificuldades em termos de infraestrutura são vistas por ele como barreiras extrínsecas. Segundo Chen; Tan e Lim (2012), as barreiras extrínsecas são consideradas de primeira ordem, pois derivam-se da inadequação e baixa flexibilidade da reconfiguração das infraestruturas das escolas. Desai e More (2014) denominam os limites infraestruturais de barreiras de segundo nível, apresentando como características a falta de equipamentos e recursos tecnológicos na escola e sua desorganização. Desse modo, a falta de acesso à internet, a falta de recursos tecnológicos, a falta de tempo para planejamento e desenvolvimento das atividades pedagógicas e a falta de habilidades para o uso dos recursos tecnológicos são mencionados no plano da infraestrutura. Apresenta ainda a falta de acessibilidade aos recursos por meio de redes, internet, a falta de um suporte e apoio técnico e a falta de um treinamento efetivo. Segundo os autores, essas barreiras impedem os professores de agregar competências para o uso eficaz dos recursos tecnológicos em situação de ensino. A falta de recursos tecnológicos encontra-se direcionada à falta de equipamentos, como computadores, projetores, laboratórios de informática, TV e som, lousa digital, vídeo conferência, entre outros.

A inexistência de um suporte técnico como apoio para os professores com os recursos tecnológicos e a falta de um treinamento efetivo, também observados nas EREMs e ETEs da RMR, mostram uma prática restrita dos professores dessas instituições, presos ao discurso tecnológico institucional e limitados à oferta para a prática de ensino. É nesta situação que as limitações se expressam, relacionada ao uso estreito de regras racionais e técnicas aplicadas à organização da 
educação, dando um caráter funcional mas pouco flexível frente mudanças e novidades, no caso, em termos de formação, insfraestrutura e ensino.

Essas barreiras encontram-se registradas nas respostas dos professores quanto aos limites e desafios para a prática docente com o uso dos recursos didático-tecnológicos. Todos os 10 (dez) professores relataram a falta de infraestrutura ou suporte técnico adequado nas escolas, seja na pergunta específica sobre os limites de incorporação das TIC, seja nas questões genéricas sobre sua prática docente, com respostas que remetem ao problema de infra-estrutura e acessibilidade. Nesta direção, Bingimlas (2009) considera que estas barreiras de falta de acessibilidade e de apoio técnico favorecem o desencorajamento de professores na integração das TIC em sua prática de ensino na era digital. Ao nível do prático, esse suporte acaba ficando a encargo do próprio professor a iniciativa para a resolução dos problemas encontrados no decorrer de suas atividades, e, ao nível da escola, em oferecer apoio técnico disponível.

No aspecto do Ensino, os limites de incorporação das TIC são vistos de formas diferentes pelos autores. Para Chen, Tan e Lim (2014) as barreiras de primeiro nível relacionadas ao ensino tratam de questões sobre a falta de confiança do professor, a falta de competência para o uso das TIC, a falta de motivação para mudar, destacando ainda a falta de percepção de que a mudança no processo de ensino-aprendizagem exigirá do professor uma modificação de seu papel e de suas práticas. De acordo com Desai e More (2014), a falta de um treinamento efetivo tem sido a mais frequente dificuldade apresentada na literatura, a saber: "Lack of effective training is frequently referred barrier in literature. There are not enough training opportunities for teachers to effective utilization of an ICT” (DESAI; MORE, 2014, p. 30).

Bingimlas (2009), por seu lado, trata os limites ligados ao ensino a partir de dois níveis: da escola e do professor. Ao nível da escola, Bingimlas (2009) destaca que um dos principais limites é a falta de um treinamento pedagógico efetivo que busque preparar o professor para usar as tecnologias em situação de ensino - assim como destacado em Desai e More (2014), e inclusive para situações de problemas técnicos. Dos 10 professores de geografia questionados, 7 responderam que não obtiveram nem curso preparatório antes do ingresso nem curso de atualização pela Secretaria da Educação. Outro limite realçado por Bingimlas (2009), que se torna um entrave, é a 'falta de tempo' dos professores no espaço escolar para o planejamento de aulas e para explorar os recursos advindos das TIC. No empírico, essa falta de tempo foi relatada por todos os professores, seja pela insuficiência da carga horária disponível, seja sobre os limites enfrentados, seja pelas condições de estresse de trabalho. 
Ao nível do professor, Bingimlas (2009) relata que várias pesquisas apontam a falta de confiança como limitador para o uso das TIC, criando obstáculo para aceitá-la em sua prática de ensino. Apresenta algumas razões, como medo, limitações no conhecimento na área das TIC e ansiedades nas salas de aulas, por não serem habilidosos no uso desses recursos tecnológicos. Outra barreira é a falta de competência do professor diretamente relacionada ao problema de formação que gera falta de confiança na integração das TIC e uma consequente limitação da sua prática docente. O autor observou em pesquisas na Dinamarca que os professores relataram a falta de competências em TIC, e por razões de pedagogia/didática, optaram por não usá-las no processo de ensino. A partir de pesquisa em escolas europeias de 27 países, no ano de 2006, Bingimlas (2009) discorre: “The findings show that teachers who do not use computers in classrooms claim that "lack of skills" are a constraining factor preventing teachers from using ICT for teaching” (BINGIMLAS, 2009, p. 238).

A resistência à mudança foi outra barreira significativa ao nível do professor, porém vista sob o olhar de algumas razões, como, por exemplo: o encorajamento ao acesso aos recursos da internet, os desafios da instantaneidade na comunicação e a falta de encorajamento na condução de novos desenvolvimentos tecnológicos, exigindo mudanças de níveis de desempenho e de práticas pedagógicas. A falta de suporte técnico e a falta de tempo para o planejamento e organização das atividades de ensino tornam-se mais um obstáculo à integração das TIC na prática docente (BINGIMLAS, 2009). Por outro lado, percebe-se que a falta de compreensão dos possíveis benefícios das tecnologias para o processo de ensino, por parte dos professores, tem dificultado a disposição dos mesmos às mudanças exigidas em sua prática pedagógica (BINGIMLAS, 2009).

$\mathrm{Na}$ presente pesquisa foi possível constatar, pelas respostas dos professores, algumas das características apresentadas pelos autores na realidade das EREMs e ETEs sobre a experiência com o uso das TIC em sua prática docente. Mas, diferente do sugerido por Bingimlas (2009), a crença da relevância e da importância dos recursos tecnológicos para o desenvolvimento do ensino e para o aprendizado discente foi observada nas respostas dos professores (Quadro 1).

Quadro 1 - Significado de tecnologia para os docentes participantes da pesquisa 


\begin{tabular}{||l|l||}
\hline \hline Respondente $\mathbf{N}^{\circ}$. & Significado de Tecnologia \\
\hline 1 & $\begin{array}{l}\text { Importante como ferramenta de aprendizagem } \\
\text { docência }\end{array}$ \\
\hline 2 & Inovações \\
\hline 3 & Técnicas para facilitar a relação aluno conteúdo \\
\hline 4 & $\begin{array}{l}\text { Não responder } \\
\text { A Tecnologia é o uso de ferramentas, a fim de promover o dinamismo em } \\
\text { varias áreas } \\
\text { Mais uma ferramenta para facilitar o trabalho docente }\end{array}$ \\
\hline 6 & $\begin{array}{l}\text { Conjunto de conhecimento e técnicas demonstrado em instrumentos e } \\
\text { equipamentos que viabilizam a vida humana }\end{array}$ \\
\hline 7 & $\begin{array}{l}\text { Aprimoramento das habilidades cognitivas e aprimoramento das práticas } \\
\text { vivenciadas } \\
\text { Auxilia o professor no complemento da atividade docente }\end{array}$ \\
\hline 10 &
\end{tabular}

Fonte: elaborado pelo autor

Contudo, tais atitudes declaradas ainda não conseguiram ser acompanhadas de uma abordagem mais ampla e efetiva por parte das instituições gerenciadoras (escolas, secretarias regionais estaduais, MEC etc), o que pode ser uma falta de preparo estrutural destes professores em lidar com as novas ferramentas. Para os professores das EREMs e ETEs os limites encontram-se predominantemente relacionadas à falta de formação e preparação para o uso das TIC em situação de ensino (Quadro 2). Entende-se que a falta de formação não se limita ao currículo, mas também se encontra vinculada à formação continuada, visando ao aperfeiçoamento do trabalho docente. Com relação à falta de percepção para a mudança, não identificamos nas respostas dos professores um posicionamento claro ou diretamente relacionado a essa questão. A questão da resistência encontrase relacionada à falta de preparação, à insegurança pela inabilidade no uso das TIC na prática de ensino. No tocante à falta de preparação para o uso das TIC, foi, ao mesmo tempo, um fator de desmotivação e também de resistência a mudanças, pois a inabilidade para o uso desses recursos pelos professores refletiu na ineficiência de suas interações intersubjetivas que favoreceriam o processo de ensino-aprendizagem.

Quadro 2- Limites da prática docente com os recursos didático-tecnológicos 


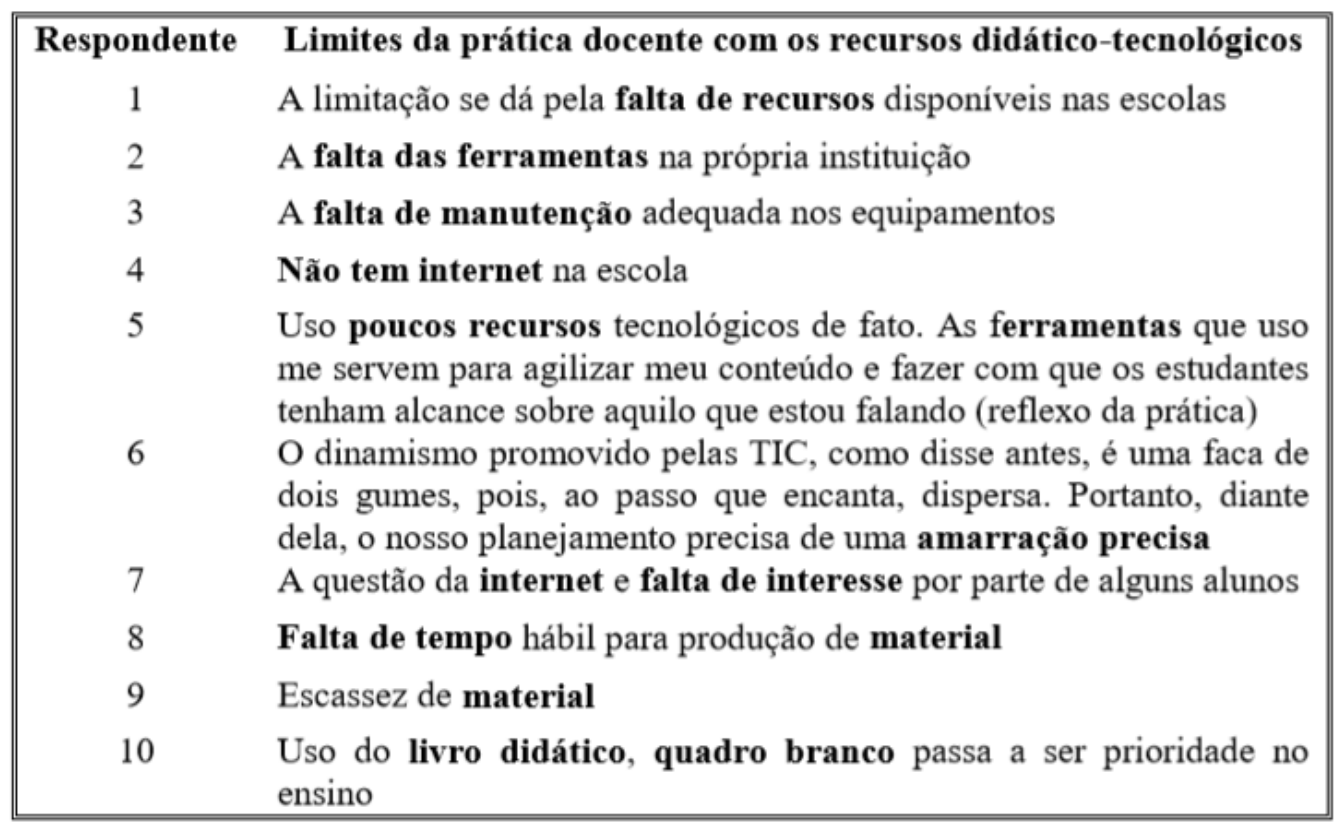

\section{Fonte: elaborado pelo autor}

Partido da análise feita por Bingimlas (2009) percebe-se que, embora se deva considerar o lapso temporal existente entre quando o estudo foi realizado e publicado pelo autor no ano de 2009, e a realização de nossa pesquisa no biênio de 2017-2018, foi possível constatar que os respectivos limites apresentados em seu estudo também se encontravam presentes, de alguma forma, na realidade dos professores das escolas participantes da pesquisa. Nas respostas apresentadas pelos professores, muitas das questões concernentes às barreiras ao nível do professor e ao nível da escola encontramse enquadradas nos limites da prática docente com os recursos didático-interativos (Quadro 2). Assim, são apresentados pelos professores a falta de recursos e de ferramentas tecnológicas, a falta de internet, a falta de tempo para o planejamento e produção das atividades, a falta de competência e de habilidades com o uso das TIC. Também foram apresentadas dificuldades de dominar as ferramentas tecnológicas nas atividades de ensino e a falta de apoio e de manutenção dos recursos e de ambientes adequados para o efetivo exercício com os recursos didático-interativos - tal como sugerido pelos autores.

Há uma outra circunstância evidenciada por Kensky (1998), que é o desconforto de situações impostas pelo uso de softwares educativos, muitas vezes não conseguindo agregar interação no processo de ensino. São processos que permeiam a prática docente, criando barreiras para a sua funcionalidade. Sabe-se que, há algum tempo, grande parte da produção dos softwares 
comercializados para o trabalho docente eram feitos por técnicos, sem uma conexão mais específica com métodos e técnicas de ensino e sem o acompanhamento e a participação de quem conhecia o cotidiano escolar. Segundo Kensky (1998) a distância estabelecida dos professores para com a produção das novas tecnologias tem favorecido à baixa qualidade didática desses programas educativos. E quando esses profissionais (professores) são desconhecedores da técnica produtiva e passam a emitir opiniões sobre o uso desses pacotes pedagógicos, tornam-se despercebidos em suas críticas pelo imperativo da técnica produzida e aplicada, submetendo o pedagógico ao caráter técnico do equipamento e ao marketing determinado pelas empresas de softwares.

Refletindo sobre essas circunstâncias, a autora faz a seguinte crítica:

Realizados por técnicos que, em geral, não entendem de educação, estes programas são impostos pelas escolas e empresas como potencialmente revolucionadores do ensino. Intimidados, os professores que desconhecem os fundamentos da técnica não são ouvidos em suas queixas e se submetem aos técnicos e aos programas de baixa qualidade educativa por eles produzidos (KENSKY, 1998, p. 70).

Considerando isso, podemos dizer, que as limitações apresentadas pelos professores de Geografia das EREMs e ETEs podem também não se restringir somente às questões infraestruturais de falta de equipamento e manutenção, ou de falta de interesse do discente. Mas pode envolver também uma "certa" estranheza com o próprio uso desses recursos e das limitações em suas interações no fluxo do ensino e da aprendizagem. Sobretudo, por não terem sido preparados para o uso efetivo dessas técnicas em sua prática de ensino. Desse modo, sem se sentirem preparados e habilidosos, e sem competências para a utilização dessas ferramentas em sua prática docente, o professor sente-se desencorajado a fazer uso desses recursos. Entretanto, percebe-se, também, que os limites apresentados pelos professores questionados são sempre colocados a partir de fatores externos a eles, ou seja, desassociado de um processo de autorreflexão da prática de ensino, que, em decorrência, poderá restringir a atuação das TIC como questões de ordem meramente técnico-instrumental, de apoio, suporte e de acessibilidade.

No entanto, convém problematizar que, embora essas limitações de infraestrutura, humanas e de ações técnico-operacionais tenham limitado o uso dos recursos didático-tecnológicos nas escolas participantes, isso não foi determinante, por si só, para restringir o desenvolvimento na aprendizagem discente. Pensando ainda numa dinâmica contraditória, na verdade o fato de algumas escolas ETEs ou EREMs, mesmo sem uma infraestrutura apropriada, sem recursos e sem ferramentas tecnológicas conseguirem obter uma boa classificação no IDEPE 2016, poderia ser visto como um possível 
caminho que nos permite refletir/afirmar que a práxis docente em suas ações interativas foi um dos principais protagonistas desse cenário. A dinamização do cotidiano, facilitada pelas TIC, posta os indivíduos numa esfera mais dinâmica de interações intersubjetivas que ainda não se reverteu em termos de prática renovada no ensino de Pernambuco.

\section{Os desafios da incorporação das TIC na prática dos professores de Geografia}

Os desafios de incorporar as TIC na prática do ensino envolvem diferentes escalas, do indivíduo-professor, da instituição-escola até a evolução da sociedade. Nesse sentido, partindo da escala global, as TIC no ensino não se desvinculam dos desafios de se viver no contexto da Revolução Tecnológica. Tal mudança possibilitou que a tecnologia trouxesse meios de legitimar as relações sociais, expandindo sua ação instrumental no espaço da cultura midiática, movida por instrumentos da ciência e da técnica e mediada pela comunicação no cotidiano das pessoas. Em decorrência, a experiência no mundo atual tem sido altamente mediada pelas novas tecnologias e o ritmo dessa experiência é cada vez mais modulado pela aceleração tecnológica.

$\mathrm{Na}$ verdade, a sociedade do século XXI passa por um processo em que a informação/comunicação acontece de forma muito acelerada e isso ocorre devido à evolução tecnológica (SANTOS e SILVEIRA, 2003). Para o ensino, nessa aceleração muitas vezes professores e alunos não vivenciam de forma diferente esse contexto, pois a simples convivência com estas tecnologias nem sempre resultam em melhores desempenhos dos seus usuários, sendo necessário prática. Lévy (2010) reforça esse entendimento ao afirmar que a plasticidade e a dinâmica do modelo informático são munidas de certa autonomia de ação e reação. Um desafio para o qual o professor precisa estar preparado para receber essa nova forma de conhecimento. Contudo, como demonstraremos, em diálogo com os autores e com as EREMs e ETEs muitos dos desafios realçados vinculam-se à superação dos limites atualmente vividos.

O manuseio pedagógico do recurso técnico é um dos que unirá o técnico e o comunicativoreflexiva na prática do ensino. Saber usufruir dessas ferramentas tecnológicas que estão presentes no cotidiano dos alunos ajudará a explicar e mostrar, de forma contextualizada os diversos saberes e possibilitar mudanças no conceito de aula, promovendo, por sua vez, uma inovação no processo de ensino. Isso exige uma transformação no método de ensino; uma mudança, aliás, operada na prática docente e já diagnosticada pela literatura internacional como desafios trazidos pelo uso de recursos didático-interativos, com vista a transformar a sala de aula (BINGIMLAS, 2009, SLONSKI e 
ROCHA e MAESTRELLI, 2017). Uma das mudanças tem sido promovida pelo uso das plataformas midiáticas.

Os desafios se revertem na busca de incorporação e destreza para com as novas mídias que, a cada dia, têm inevitavelmente ganhado espaço no cotidiano e no campo do ensino. A busca é de ampliar a dinâmica da prática docente e do processo de ensino e de aprendizagem, expandindo os instrumentos da mediação pedagógica.

$\mathrm{O}$ ato de ensinar e aprender ganha novo suporte com o uso de diferentes tipos de software educacional, de pesquisa na Internet e de outras formas de trabalho pedagógico com o computador. Desse modo, é inegável que a escola de hoje precisa promover mudanças sintonizadas com esse novo contexto, a fim de garantir a apropriação crítica das novas tecnologias de informação e comunicação (NTs) disponibilizadas para o processo educacional (Grégoire et al. 1996) diante das novas possibilidades que elas descortinam (OLIVEIRA, COSTA e MOREIRA, 2001, p. 10).

As recentes tecnologias vêm dinamizando os processos de aprender e ensinar em face dos atuais mecanismos de facilidade, velocidade, instantaneidade e simultaneidade que estão encarnadas nas TIC. A prova disso são os hipertextos. Recursos tecnológicos que permitem uma dinâmica conexão e interação com várias plataformas de informações e aportes midiáticos sobre determinado assunto, tema e contexto. Segundo Lévy (2010):

O hipertexto ou a multimídia interativa adequam-se particularmente aos usos educativos. É bem conhecido o papel fundamental do envolvimento pessoal do aluno no processo de aprendizagem. Quanto mais ativamente uma pessoa participar da aquisição de um conhecimento, mais ela ira integrar e reter aquilo que aprender. Ora, a multimídia interativa, graças à sua dimensão reticular ou não linear, favorece uma atitude exploratória, ou mesmo lúdica, face ao material a ser assimilado. É, portanto, um instrumento bem adaptado a uma pedagogia ativa (LÉVY, 2010, p. 40).

Os desafios da prática docente com o uso destas tecnologias encontram-se dentro de um projeto inovador, com as tecnologias facilitando o processo de ensino e aprendizagem. Mesmo sendo técnica, sensibilizam pessoas para novos assuntos, trazendo informações novas, diminuindo a rotina, ligando-as com o mundo, aumentando sua interação (redes eletrônicas). Sua operacionalidade permite a personalização (adaptação ao ritmo de trabalho de cada aluno) da aprendizagem e melhor comunicação com o aluno, trazendo para a sala de aula as linguagens e meios de comunicação do diaa-dia (MORAN; MASETTO; BEHRENS, 2000).

Para lidar com as inovações e operacionalidades, os desafios de envolvimento, formação e infraestruturação já estão sendo vividos - apresentando-se correlacionados. A inclusão das TIC no 
cotidiano escolar, no chão da sala de aula, é um dado irreversível, de forma que a cada dia, e com mais frequência, tem-se percebido a adesão das TIC de escolas - inclusive incluindo-as em sua proposta curricular. A inclusão dessas tecnologias tem exigido do professor um mínimo de conhecimento para poder utilizá-las em sala de aula, exigindo uma qualificação para o uso eficiente desses recursos. Essas mudanças têm sido mais desafiadoras aos professores que se formaram há mais de duas décadas e que se encontram em atividade, e não tiveram conhecimento de alguns recursos tecnológicos em sua formação, como por exemplo, as geotecnologias. São profissionais que não obtiveram uma formação continuada, restringindo-se, muitas vezes, a acompanhar pelo livro didático as informações advindas do SIG e de outros recursos de geoprocessamento, limitando-se a repassar as informações aos alunos, sem uma interatividade mais ampla ou conhecimento mais aprofundado (MAIO e SETZER, 2011).

Nesse contexto, para se encontrar "atualizado" com o sistema produtivo, os professores têm o desafio de buscar aliar a sua prática pedagógica à emergência dos recursos tecnológicos e às novas vivências geográficas. O caminho, portanto, envolve outras dimensões além do currículo, pois é pertinente articular a realidade social dos alunos aos conhecimentos geográficos em seu cotidiano (transformado pelas TIC).

De forma ampliada a literatura nacional tem sinalizado como meta superar algumas insuficiências de recursos técnico-pedagógicos presentes no cotidiano dos professores de Geografia, oferecendo desafios para sua prática de ensino nesses níveis. A presença de alguns softwares e hardwares, e de laboratórios de informática, embora sejam recursos em potencial para a prática docente, ainda tem oferecido obstáculos em seu uso na prática dos professores, por questões de cunho operacional (dificuldades no manuseio). Mesmo assim, tem-se reconhecido a importância do computador como instrumento presente em nosso cotidiano, e que tem auxiliado a inovação no ensino de Geografia, principalmente quando se encontra conectado com as ferramentas e recursos didáticointerativos no espaço de fluxo da internet, pois, segundo Castells (2003, p. 53), a rede Web tornou-se um espaço de interconexão interativa para a vida social, tornando-se "espinha dorsal de nossas vidas".

Para o espaço escolar STÜRMER (2011) apresenta três desafios: (1) o primeiro encontra-se relacionado à construção de conhecimentos geográficos (mostrando as implicações) numa escala do global para o local; (2) o segundo está relacionado à incorporação das TIC ao cotidiano das aulas, contribuindo, segundo o autor, para uma aprendizagem efetiva do aluno, buscando maiores interações a partir dos recursos didático-interativos disponibilizados; (3) o terceiro desafio apresentado está relacionado à junção dos dois primeiros desafios, buscando, a partir das informações obtidas, 
construírem conhecimentos geográficos que contribuam para as habilidades e competências dos alunos e, ainda, a terem uma visão/percepção crítica sobre a configuração do espaço geográfico pelo uso das TIC.

A análise apresentada por Stürmer (2011) traz suas vivências na implantação de laboratórios de informática em escolas do Rio Grande do Sul e nas informações advindas do período quando atuou como professor e assistente técnico-pedagógico em escola estadual de Santa Catarina. Além dos desafios apresentados, o autor ressalta ainda outro desafio: a preparação teórico-metodológica do professor de Geografia para o uso das TIC. Adverte sobre a necessidade de investimentos em tecnologias e na capacitação dos professores para utilização dos recursos midiáticos, possibilitando novas metodologias voltadas para o ensino (desafio ao nível do professor/ensino), bem como investimentos ao nível do espaço escolar, na adequação de seus ambientes, com recursos disponibilizados para a prática docente (desafio ao nível da escola/ infraestrutura) (STÜRMER, 2011)

Além da escala da escola, os desafios também envolvem a postura do indivíduo-professor na prática docente. Oliveira (2012) focaliza a ação docente vinculada ao campo das competências didático-pedagógicas, valorizando a tomada de iniciativa do professor em busca de uma qualificação de seus saberes profissionais para o ensino crítico de Geografia. A questão agora se vincula ao desenvolvimento de ações reflexivas na prática docente, de articulação dialógica entre as concepções teórico-metodológicas de formação acadêmica e os ensinamentos da geografia escolar. Para isso, fazse necessário que os professores desenvolvam competências e habilidades para inovar os métodos de ensino, qualificando-se para utilizar os múltiplos recursos disponíveis como instrumentos de mediação pedagógica a partir do cotidiano dos alunos. Ou seja, em meio a todo esse processo de reestruturação, reelaboração e transformação do conhecimento na sociedade contemporânea, os desafios na prática dos professores também têm sido apresentados no plano da mediação pedagógica, visando a um ensino crítico, por uma transposição didática dos conhecimentos geográficos a partir da dimensão do cotidiano e dos espaços sociais vividos pelos alunos (OLIVEIRA, 2012).

Outro desafio que podemos destacar é o aperfeiçoamento dos cursos em Ensino à Distância (EAD) que as TIC favorecem. A pretensão é que o curso possa carregar o máximo de relação intersubjetiva, de interação entre alunos e professores, mesmo que à distância. Na Europa foi percebido que as TIC trouxeram mudanças estruturais na formação acadêmica, oferecendo cursos na modalidade e-learning (ensino a distância) (HARRISON, 2010). A implantação destes cursos se esforçou em fornecer, por meio de plataforma virtual, o acesso a informações e a recursos tecnológicos (fóruns de discussão, informações, publicar avisos, recursos/internet, etc.,), com vista a 
promover uma maior interação entre professores e alunos. Diferente da modalidade presencial, cuja interação é mais física, na modalidade à distância a busca é por desenvolver a autonomia no aluno.

$\mathrm{Na}$ aula presencial a dinâmica e a liderança física do professor, mediada por uma linguagem verbal e não-verbal, tornam-se indispensáveis para tornar a aula atrativa e despertar o interesse dos alunos pelos conteúdos trabalhados, mobilizando debates e conduzindo discussões entre os participantes. No ensino a distância a realidade é diferente. Há outras formas de comunicação entre professores e alunos. Nessa modalidade não há constantemente uma explicação falada, mas sim escrita, com os fóruns sendo o palco dos debates, sem liderança física do professor. Os conhecimentos e as informações são disponibilizados por meio de recursos das plataformas e de materiais escritos oferecidos, como, por exemplo, e-books. Nesse contexto, os alunos entram em contato com os conhecimentos pelos recursos e materiais que foram liberados na plataforma pelo professor, exigindo, assim, a promoção de uma educação que também ensine a iniciativa autônoma para seu desenvolvimento cognitivo (BADIA; PALLÀRES; LLURDÉS, 2006).

Segundo Jeronen e Jeronen (2008), o uso das TIC no ensino de Geografia apresentou experiências "positivas" e "negativas" que, em nossa compreensão, oferecem subsídios de análise para identificar desafios com o uso dessas ferramentas. As experiências positivas encontram-se relacionadas em termos de (1) flexibilidade (não dependência do tempo e do espaço); (2) aquisição de habilidades para o uso das TIC; (3) capacidade de melhorar a motivação; (4) diferenciação no ensino (diversidade de recursos). As experiências negativas encontram-se relacionadas à (1) falta de contatos sociais (diminuição da interação); (2) distância do professor (a autoridade do professor não está presente); (3) maior recorrência de mau-entendimentos; (4) problemas técnicos (suporte); (5) métodos de ensino unilaterais (JERONEN; JERONEN, 2008). Percebemos que, mesmo no caso específico do ensino de Geografia, as características apresentadas, tanto „positivas ${ }^{\text {ee }}$ quanto „,negativas ${ }^{e e}$, tratam-se de questões amplas, em termos de projetos. Nas experiências expostas neste projeto educacional, Jeronen e Jeronen (2008) destacaram alguns desafios para os professores envolvidos com o uso das TIC na Geografia: - garantir um contínuo desenvolvimento da infraestrutura para o uso das TIC no ensino; - ampliar as atividades da sala de aula para espaços externos à escola, com diferentes participantes - por exemplo, a presença de pais, cientistas e profissionais de negócios em atividades na escola. Todavia, chamamos a atenção para o desafio de garantir um contínuo desenvolvimento com o uso das TIC, evidenciando-se a importância dos investimentos em tecnologias e infraestrutura e, também, na qualificação dos professores para o uso desses recursos (TIC). 
Todas essas questões permeiam as reflexões sobre os desafios com que as atividades pedagógicas, em particular a prática docente, irão se deparar no curso de suas atividades profissionais. Perpassam, entre outras questões, pela criação de ambientes de aprendizagem, com novas formas de aprendizado, interligando recursos, imagens e ideias que reflitam na construção do próprio conhecimento com o uso dos recursos tecnológicos no chão da sala de aula. Ou seja, dentro da realidade educacional em que o processo de ensino se desenvolve, instruindo e socializando saberes, mediando conflitos e buscando internalizar uma aprendizagem com resultados e, ainda, numa constante busca para superar as "possíveis" estranhezas com o próprio uso desses recursos e das limitações em suas interações no fluxo do ensino e da aprendizagem.

Quadro 3 - Desafios apresentados pelas TIC para promover a aprendizagem dos conhecimentos geográficos nas ETEs e EREMs da RMR

\begin{tabular}{||ll||}
\hline Respondente & $\begin{array}{l}\text { Desafios apresentados pelas TIC para promover a aprendizagem } \\
\text { Nos conhecimentos geográficos nas ETEs e EREMs da RMR } \\
1\end{array}$ \\
2 & Falta de estrutura na escola \\
3 & Como prender a atenção para o uso efetivo voltado para os estudos \\
4 & Permanecer multi conectado e bem informado \\
5 & Superar a falta de estrutura oferecida pela Secretaria de Educação \\
6 & Manuseio \\
& Competências para acompanhar o dinamismo das TIC, pois ao \\
7 & passo que encanta também dispersa. \\
8 & Dificuldades em dominar algumas ferramentas \\
& Planejamento e tempo de aula, visto ter um conteúdo e pouco \\
9 & tempo pedagógico \\
& Conseguir mesmo com a escassez de equipamentos, tornar a aula \\
10 & um momento de identificação do estudante \\
\hline
\end{tabular}

Fonte: elaborado pelo autor

No quadro acima, as respostas apresentadas pelos professores das escolas ETEs e EREMs nos trazem a conexão existente entre os desafios e os limites da prática docente no uso dos recursos didático-tecnológicos. Fica perceptível que a falta de estrutura em algumas escolas participantes da pesquisa traz à reflexão uma realidade que, de modo geral, permeia a educação no Brasil, e que também ultrapassa as suas fronteiras. Conforme estudo apresentado por Bingimlas (2009), a partir de uma revisão de literatura internacional que tratava das barreiras, como Chen; Tan e Lim (2012) e Desai e More (2014) mostraram realidades muito próximas ao diagnosticado em nossa pesquisa, não sendo, portanto, um caso isolado da Secretaria de Educação do Estado de Pernambuco. 
A hegemonia de uma interpretação técnico-instrumental dos professores, sob influência do caráter funcional da racionalidade técnica, não é oposta e se associa à busca por práticas mais intersubjetivas (expressa nas estratégias da tabela 1), típicas de uma racionalidade pedagógica. Entretanto, demonstra que as ações dessas estratégias ainda não atenderam às demandas das próprias escolas ETEs e EREMs participantes e, consequentemente, das metas de seus gestores, do corpo docente e do próprio processo de ensino previsto para o alcance dos índices esperados. Em termos de TAC, isso é típico do Sistema colonizando o Mundo da Vida. No entanto o Mundo da Vida resiste, pois percebemos que, entre as escolas participantes ETEs e EREMs da RMR, existe, em destaque, uma escola da categoria EREM (ver quadro 1), que, mesmo não dispondo de uma infraestrutura adequada, com recursos e equipamentos tecnológicos para os fins e objetivos almejados

Nesse sentido, entende-se que os desafios para atingir uma aprendizagem de resultados ultrapassam os próprios limites da disponibilidade de recursos tecnológicos e da infraestrutura dos ambientes informatizados e adequados para o uso das TIC. Percebe-se, ainda, que os desafios também avançam no campo da superação da falta dos recursos tecnológicos e dos ambientes propícios para seu uso. São diversas realidades que se diferenciam de escola para escola e de ator para ator, mas que tem revelado possíveis caminhos para se compreender a superação desses limites e enfrentamento dos desafios na prática docente.

\section{Considerações Finais}

Os limites e desafios identificados na incorporação das TIC na prática docente têm diferentes espacialidades e contextos de expressão, com questões que envolvem diretamente a formação do professor, o ensino e a infraestrutura do ambiente escolar. A superação e enfrentamento de tais aspectos repercutem também na necessidade de procedimentos teóricometodológicos, na prática de ensino dos professores, para articular os conhecimentos disponíveis advindo de sua formação acadêmica e da ,avalanche ${ }^{\text {ee }}$ de informações do cotidiano dos alunos advindo de notícias, imagens, vídeos e textos pelas TIC. Pelas possibilidades que oferecem, permitem fazer a conexão entre os temas geográficos e interação dos sujeitos, a fim de que espaços intersubjetivos, críticos e reflexivos venham a ser despertados/construídos, ou seja, que passem a agregar envolvimento e interação entre professores e alunos para o conhecimento dos processos geográficos, no fluxo do ensino e da aprendizagem. 
Em termos de limites na formação docente, a formação do professor de Geografia não tem correspondido à realidade do mercado de trabalho, nem à velocidade de mudanças e aperfeiçoamentos ocorridos, no caso, das TIC. As mudanças ocorridas na sociedade globalizada são bem diferentes para quem se formou há quase duas décadas e continua ativo em sala de aula (como é o caso de professores pesquisados), buscando a ressignificação de práticas pedagógicas para atender as exigências de um mercado, contudo sem o preparo adequado. A influência de uma racionalidade instrumental hegemônica ainda se agrava pela necessidade de cumprimento de objetivos pragmáticos, ou seja, que precisam dar conta em termos produtivos para atender às exigências das políticas de resultado, vinculadas a uma lógica normatizadora preponderante nas instituições educacionais públicas e privadas. Neste contexto, embora exista um aparente esforço para uma qualificação docente, por uma formação continuada, por iniciativa própria ou institucional, ainda hoje o currículo do professor de Geografia não tem dado conta de atender as lacunas existentes para o uso das TIC em sua prática de ensino, pela reduzida quantidade de componentes obrigatórios e, em alguns casos, pela inexistência deles para atender as exigências dos meios produtivos. Desse modo, o processo de interação com as ferramentas tecnológicas não consegue avançar mais rapidamente, passando a lidar com empecilhos e barreiras, por inseguranças geradas pelas competências e habilidades que deixaram de ser construídas na formação do professor (acadêmica/continuada), deixando de alinhar a prática docente à percepção e vivência das mudanças na sociedade.

Percebeu-se que muitos dos limites e desafios presentes no processo de integração das TIC têm sido observados ao nível do ensino e da infraestrutura. E isso tem sido apontado como um fenômeno global, pois tem ocorrido em vários lugares do mundo em diferentes momentos, conforme foi apresentado pelas literaturas consultadas neste trabalho. Foi possível constatar alguns desses limites e desafios e correlacioná-los com os identificados pela literatura internacional - muitos já conhecidos na Europa há aproximadamente duas décadas. Para citar alguns, temos novamente a falta de formação e preparação para o uso das TIC em situação de ensino (relacionado ao currículo); falta de equipamentos e de ambiente físico adequado (relacionado à infraestrutura); falta de recursos tecnológicos, planejamento e organização para o uso das TIC (relacionado à infraestrutura e ao ensino); falta de suporte e de treinamento efetivo (relacionado à infraestrutura e ao ensino); e a falta de percepção à mudança (relacionada à reflexividade sobre a prática docente/professor).

\section{REFERÊNCIAS}


BADIA, A.; PALLÀRES, M.; LLURDÉS, J.C. The use of new technology in teaching geography in the EHEA: The subjects of Social and Economic Geography, Cartography and Photointerpretation, and GIS. Digithum [online article]. Iss. 8. UOC. Catalunya, 2006.

BINGIMLAS, Khalid Abdullah. Barriers to the Successful Integration of ICT in Teaching and Learning Environments: a review of the literature. Eurasia Journal of Mathematics, Science \& Technology Education. VIC. Austrália, v 5 (3), p. 235-245, mar. 2009.

BOUFLEUER, José Pedro. Pedagogia da ação comunicativa: uma leitura de Habermas. 3.ed. Ijuí: Ed. Unijuí, 2001.

CASTELLS, Manuel. A galáxia da internet: reflexões sobre a internet, os negócios e a sociedade. Rio de Janeiro: Zahar, 2003.

CHEN, W; TAN, A; LIM C. Extrinsic and intrinsic barriers in the use of ICT in teaching: A comparative case study in Singapore. In M. Brown, M. Hartnett \& T. Stewart (Eds.), Future challenges, sustainable futures. In Proceedings ascilite, Wellington, New Zealand, p. 191-196, nov. 2012.

DESAI, S. V; MORE, A. D. Barriers to Successful ICT Integration into TeachingLearning Environment. International Journal of Research in Advent Technology. Índia, v 2, n 2, fev. 2014. GUZMAN, M. F. D, at al. Difficulties faced in teaching Geography lessons at public secondary schools. IOSR Journal Of Humanities And Social Science. Philippines, v. 22, n. 9, (7), p. 64-70, set. 2017.

HARRISON, David. Teacher factors influencing classroom ICT use. In: Developing use of ICT to enhance teaching and learning in East African schools: a review of the literature. Centre for Commonwealth Education \& Aga Khan University Institute for Educational Development Eastern Africa / University of Cambridge, 2010.

KENSKI, Vani Moreira. Novas tecnologias: o redimensionamento do espaço e do tempo e os impactos no trabalho docente. Revista Brasileira de Educação Geográfica. Campinas, n. 8, p. 5871, maio/ago., 1998.

JERONEN, Eila Sirpa Anttila-Muilu; JERONEN, Juha. Problemas and challenges in the usageof ict in biology and geography in schools and teacher education in Finland. Problems of Education in the 21st Century. Lithuanian, v. 5, 2008.

LÉVY, Pierre. As tecnologias da inteligência: o futuro do pensamento na era da informática. Tradução de Carlos Irineu da Costa. 2 ed. São Paulo. Ed. 34, 2010.

MAIO, Angelica Carvalho Di; SETZER, Alberto W. Educação, Geografia e o desafio de novas Tecnologias. Revista Portuguesa de Educação. Portugal, v 24 (2), p. 211-241, mai. 2011.

MARTINAZZO, Celso José. Pedagogia do entendimento intersubjetivo: razões e perspectivas para uma racionalidade comunicativa na Pedagogia. Ijuí: Unijuí, 2005.

MORAN, José Manuel; MASETTO, Marcos T. e BEHRENS, Marilda Aparecida. Novas tecnologias e mediação pedagógica. Campinas: Papirus, 2000.

NEITZEL, Odair. Educação e racionalidade comunicativa na sociedade da informação. Theoria Revista Eletrônica de Filosofia. Porto Alegre, v. 6, n. 16, p. 143-158, jul. 2014.

OLIVEIRA, A. C. C. A. Competências didático-pedagógicas para o ensino de geografia e os desafios à prática docente. In VI Colóquio Internacional - Educação e Contemporaneidade. Sergipe, 20 a 22 de setembro, 2012.

OLIVEIRA, Celina Couto; COSTA, José Wilson da; MOREIRA, Mercia. Ambientes informatizados de aprendizagem: produção e avaliação de software educativo. Campinas: Papirus, 2001.

SANTOS, Francisco Kennedy Silva dos. Limites e Possibilidades da Racionalidade Pedagógica no Ensino Superior. Educação \& Realidade, Porto Alegre, v. 38, n. 3, p.915-929, jul./set. 2013. 
SANTOS, Milton e SILVEIRA, Maria Laura. O BRASIL - Território e a sociedade no início do século XXI. Rio de Janeiro: Record, 2003.

SANTOS, Suâmi Abdalla. O potencial da tecnologia audiovisual aplicada ao ensino de geografia. Revista Brasileira de Educação Geográfica. Campinas, v. 4, n. 7, p. 57-69, jan./jun., 2014.

SLONSKI, T. G; ROCHA, A. L. F; MAESTRELLI, S. R. P. A racionalidade técnica na ação pedagógica do professor. In: Encontro Nacional de Pesquisa em Educação em Ciências, 11, 2017, Florianópolis. Anais eletrônicos... Florianópolis: UFSC, 2017.

STÜRMER, Arthur Breno. As TICs nas escolas e os desafios no ensino de geografia na educação básica. Geosaberes, Fortaleza, v. 2, n. 4, p. 3-12, ago. / dez. 2011. 